\title{
La gestión de la comunicación y las relaciones públicas entre los gobiernos y las comunidades indígenas: Colombia, un caso de estudio
}

\author{
The management of communication and public relations between \\ governments and indigenous communities: Colombia, a case study
}

\author{
Yesenia Serpa Navarro ${ }^{1}$ \\ yeseniaserpa@odysse.es
}

Recepción: 04/06/18 Revisión: 04/06/18 Aceptación: 18/06/18 Publicación: 31/06/18

\section{Resumen}

En la década de los 80 comenzó un lento y arduo camino en el proceso de organización indígena en América Latina. Los pueblos originarios emergieron del silencio y del paternalismo de los gobiernos y crearon un nuevo discurso del indio para el mundo. Descubren que "influir en las mayorías puede ser de gran ayuda" (Bernays, 2008). Este nuevo discurso debía ser identitario, entendido por la sociedad occidental con sus códigos de conductas, símbolos y entresijos. Un discurso con un camino de ida y de regreso porque buscaba comunicar y establecer una relación de alianza y reciprocidad. Tres décadas después, el alegato de autenticidad del pueblo indígena es interiorizado por el gobierno colombiano en su propia propaganda política para ganarse a la opinión pública internacional y al mismo tiempo para hacer frente a un enemigo en común: el conflicto armado.

Palabras claves: Comunicación, Relaciones Públicas, Gobierno colombiano, comunidades indígenas, discurso.

\begin{abstract}
In the 1980s, a slow and arduous journey began in the process of indigenous organization in Latin America. The native people emerged from the silence and paternalism of governments

\footnotetext{
${ }^{1}$ Directora General de ODYSSE Servicios \& Asesoría S.L. Especialista en Revisoría Fiscal y Auditoría Externa; MBA en Protocolo, Relaciones Institucionales y Organización de Eventos. Especialista en Oratoria con Inteligencia Emocional y Programación Neurolingüística. Autora del Blog "Protocolo entre lo profano y lo sagrado" y del manuscrito no publicado "Ceremonial del ciclo vital de las etnias kogui y arhuaca de la Sierra Nevada de Santa Marta, Colombia".
} 
and created a new discourse of the Indian for the world. They discover that "influencing majorities can be very helpful" (Bernays, 2008). This new discourse should be an identity, understood by Western society, with its codes of conduct, symbols and intricacies. A discourse with a path of return but also of return because it sought to communicate and establish a relationship of alliance and reciprocity. Three decades later, the allegation of the indigenous people echoes in the Colombian government who uses their rhetoric to reach the masses in favor of a common enemy: the armed conflict.

Keywords: Communication, Public Relations, Colombian government, indigenous communities, speech.

\section{Sumario}

1. Introducción

2. Desarrollo

3. Conclusiones

4. Bibliografía

\section{INTRODUCCIÓN}

Comunicar es algo más que establecer un diálogo entre una o varias personas. Comunicar es mostrarle al otro (receptor) nuestra (emisor) percepción de la realidad. Una realidad que no siempre es coincidente con la suya. Establecer una comunicación asertiva entre personas de una misma cultura y una misma lengua ya es una actividad compleja pero si el dialogo se genera entre culturas diferentes, cuya relación ha estado marcada por sucesos en donde el despojo ha sido el hilo conductor de la misma, éste necesita de un protocolo que ayude a entender, comprender y sobre todo a respetar esas diferencias.

Colombia, podría considerarse un país "híbrido" producto del choque cultural entre indígenas y españoles. Un país mestizo que tiene en su extenso territorio un legado ancestral de quienes fueron sus primeros pobladores. Zonas que durante años han sido asediadas por su valor arqueológico, por su ubicación estratégica en el desarrollo del conflicto armado y por su valor económico en recursos minerales. Así pues, los territorios indígenas han estado presentes en la agenda política del gobierno colombiano por una causa o por otra. De ahí la importancia de la gestión de la comunicación entre éste y sus dirigentes, objetivo principal de esta investigación.

Para alcanzar este objetivo principal se requiere del desarrollo de los siguientes objetivos secundarios: 
1. Contextualizar desde un punto de vista histórico, social y político las fases de la emergencia indígena colombiana.

2. Determinar el protocolo aplicado por el gobierno de Juan Manuel Santos Calderón para una comunicación intercultural eficaz con las comunidades indígenas.

3. Analizar el uso de la imagen y de la problemática ambiental como elementos de persuasión del nuevo discurso indigenista.

La metodología utilizada en esta investigación es documental. Incluye revisión de fuentes bibliográficas, hemerográficas, declaraciones y convenios de organismos nacionales e internacionales.

\section{DESARROLLO}

\subsection{Contexto socio-político}

Desde la ocupación de Abya-yala ${ }^{2}$, término utilizado por las organizaciones indígenas para hacer referencia al continente americano, los pueblos originarios tienen en su haber una larga y dura batalla por la restitución de sus tierras, el respeto a su cultura y el reconocimiento de su autonomía. Tres conceptos -territorio, cultura y autogobierno- sobre los cuales viene trabajando la agenda política internacional desde la década de los 80 y que ha encontrado en la problemática medioambiental al mejor de los aliados.

Colombia es considerado unos de los países con mayor diversidad biológica y étnica. En su extenso territorio se encuentran distribuidos 84 pueblos originarios con una población de $1.378 .884^{3}$. Sin embargo, la Organización Nacional Indígena de Colombia (ONIC) tiene contabilizados a 102, de los cuales 18 se encuentran aislados y en peligro de extinción. Aunque en la actualidad la comunicación entre el gobierno colombiano y las comunidades indígenas es bidireccional, la historia demuestra que no siempre ha sido así y que la violencia ha sido el medio con que los colonos, terratenientes, multinacionales (empresas de extracción minera y maderera), el ejército y los grupos al margen de la ley se han apropiado de territorios ancestrales bien sea por su riqueza en combustibles fósiles o por su ubicación estratégica para el resguardo de los actores del conflicto armado.

\footnotetext{
${ }^{2}$ Aby-ayala es un término lingüístico de origen chibcha con el que los Kuna (grupo amerindio asentado en Colombia y Panamá), desde sus orígenes, hacen referencia al continente americano. Este vocablo ha sido reconocido y aceptado por las asociaciones, organizaciones e instituciones indígenas de América Latina y significa tierra en plena madurez, tierra vital o tierra noble que acoge a todos. Comisión Económica para América Latina y el Caribe, 2017. Los pueblos indígenas en América (Abya Yala). Desafíos para la igualdad en la diversidad. CEPAL, Santiago.

${ }^{3}$ Este dato corresponde al último Censo General realizado por el Departamento Administrativo Nacional de Estadística - DANE en el año 2005. Cuadro 4.11, P. 130. http://www.dane.gov.co/files/censos/libroCenso2005nacional.pdf
} 
La gestión de la comunicación entre el gobierno colombiano y las comunidades indígenas ha estado marcada por fases en las que la población indígena, especialmente la asentada en la Sierra Nevada de Santa Marta, Cauca y Putumayo han sido sometidas a la violación de sus derechos fundamentales y a la profanación de sus territorios. Un arduo camino que encuentra en el gobierno de Juan Manuel Santos Calderón el mejor de los escenarios para reivindicar la cultura y para mostrarla, a través de sus ritos y ceremonias, a la comunidad internacional.

A continuación se describen las fases del proceso de comunicación socio-político entre el gobierno colombiano y las comunidades indígenas desde 1970 hasta la actualidad.

\subsubsection{Primera fase. 1970 -1982. Organización Internacional Indígena de Colombia- ONIC}

Pese a que Manuel Quintín Lame ${ }^{4}$, reconocido líder de origen nasa, promoviera un levantamiento indígena entre los años 1914 y 1918 y a partir de entonces iniciaría una lucha incansable que le llevaría a estar encarcelado en diversas ocasiones y, que en 1961 se instaurara la Ley 135 "Sobre reforma social agraria" en la cual los grupos indígenas se verían notablemente beneficiados con la constitución de resguardos (Ministerio de Justicia de la República de Colombia, 1961). Solo hasta 1971 con la creación del Consejo Regional Indígena del Cauca -CRIC- las comunidades iniciarían su participación de manera activa en la vida socio-política del país.

El primer paso de la CRIC en su comunicación estratégica con el gobierno fue el de contribuir con el censo nacional que se realizó en el año 1972, censando a la población indígena. Dos años después, en 1974, organizaría el Primer Encuentro Nacional Indígena de Colombia y en enero de 1975 sería el precursor de "Unidad Indígena" ${ }^{5}$, el primer periódico de circulación nacional. Con el empoderamiento de la CRIC surgen nuevas asociaciones indígenas que emergen desde el silencio para fundar en 1982 la ONIC - Organización Internacional Indígena de Colombia- .

4 Manuel Quintín Lame, cacique de los paeces promovió un movimiento indígena entre 1910 y 1918 contra el terraje, una forma de trabajo en el que el indígena debía trabajar en las haciendas de los colonos durante varios días a la semana sin remuneración ni contraprestación alguna a cambio de una pequeña parcela que les era cedida en usufructo. Lame elaboró el siguiente programa, el cual ha influido de manera significativa en el movimiento indígena actual:

La recuperación de las tierras de los resguardos.

- La ampliación de las tierras de los resguardos.

- El fortalecimiento de los cabildos.

- El no pago del terraje.

- Dar a conocer las leyes sobre indígenas y exigir su justa aplicación.

- Defender la historia, la lengua y las costumbres indígenas.

- Formar profesores indígenas.

${ }^{5}$ Unidad Indígena nace como idea en el Tercer Congreso campesino de la ANUC celebrado en Bogotá del 1 al 4 de septiembre de 1974. Su objetivo principal era el de mantener informados a todas las comunidades indígenas del país sobre los acontecimientos de la CRIC y demás organizaciones indígenas. (Sánchez, E. \& Molina, H. (Comp.) (2010). 


\subsubsection{Segunda fase. 1983 - 1991. Reconocimiento}

La segunda fase tiene como eje principal dos acontecimientos: La formación de la primera guerrilla indígena de Colombia y de Latinoamérica y la participación sin voto de tres líderes indígenas en la Asamblea Nacional Constituyente. Ambos acontecimientos, por diferentes medios, buscaban el reconocimiento de los territorios y de la autonomía.

El primero de ellos se da 1985 en el Municipio de Buenos Aires, departamento del Caquetá. En un hecho sin precedentes por parte de las comunidades indígenas, 80 personas cansadas del olvido del gobierno, de la violencia y la incursión de la guerrilla en sus territorios toman las armas e inician una revolución bajo el nombre: "Comando Quintín Lame. Por la defensa de los derechos indígenas", justo cuando el gobierno de Colombia establecía diálogos de paz con dos grupos subversivos: El Movimiento 19 de abril (M-19) y el Ejército Popular de Liberación (EPL) ${ }^{6}$. En mayo de 1991, los dirigentes del Comando negocian con el gobierno de Cesar Gaviria Trujillo el desarme del mismo a cambio de su participación en la Asamblea Nacional Constituyente, en donde estuvieron representados por el indígena de origen Nasa Alfonso Peña. También participaron Lorenzo Muelas de la CRIC y Francisco Rojas Birry de la ONIC.

En la Constitución Política de 1991 (Art.7), el Estado colombiano, reconoce a los pueblos indígenas como etnias. También les reconoce sus lenguas y dialectos como idioma oficial en su territorio y la enseñanza que en ellos se imparta con tradiciones lingüísticas propias será bilingüe (Art. 13). Han sido muchos los cambios que la actual Constitución ha implementado a favor de los pueblos indígenas. Grandes cambios que tuvieron su origen en la 76ạ reunión de la Conferencia General de la Organización Internacional del Trabajo "OIT" celebrada en Ginebra en 1989. En esta reunión se aprobó el Convenio 169 sobre pueblos indígenas y tribales en países independientes a través de la Ley 21 de 1991, en el cual el Gobierno Nacional acepta reconocer y proteger los derechos fundamentales de las etnias, lo que les ha permitido una amplia participación en la vida política y social del país. El primer paso para garantizar estos derechos consistía en definir una serie de conceptos esenciales para determinar el contexto sobre el que se desarrollarían los programas de inclusión social de las mismas. Para ello, el Ministerio de Agricultura en el Artículo 2, Capítulo 1 del Decreto 2164 de 1995, establece las siguientes definiciones:

a) Territorio indígena: Son las áreas poseídas en forma regular y permanente por una comunidad, parcialidad o grupo indígenas y aquellas que, aunque no se encuentren poseídas en esa forma, constituyen el ámbito tradicional de sus actividades sociales, económicas y culturales.

b) Comunidad o parcialidad indígena: Es el grupo o conjunto de familias de ascendencia amerindia, que tienen conciencia de identidad y comparten valores, rasgos, usos o

\footnotetext{
${ }^{6}$ Peñaranda, D. (2015). Guerra propia, guerra ajena. Conflictos armados y reconstrucción identitaria en los Andes colombianos. El movimiento armado Quintín Lame. Bogotá. Centro Nacional de Memoria Histórica.
} 
costumbres de su cultura, así como formas de gobierno, gestión, control social o sistemas normativos propios que la distinguen de otras comunidades, tengan o no títulos de propiedad, o que no puedan acreditarlos legalmente, o que sus resguardos fueron disueltos, divididos o declarados vacantes.

c) Reserva indígena ${ }^{7}$. Es un terreno baldío ocupado por una o varias comunidades indígenas. Fue delimitado y legalmente asignado por el Instituto Colombiano de Reforma Agraria "INCORA", para que ejerzan en él los derechos de uso y usufructo con exclusión de terceros. Las reservas indígenas constituyen tierras comunales de grupos étnicos, para los fines previstos en el artículo 63 de la Constitución Política y la Ley 21 de 1991.

d) Autoridad tradicional. Las autoridades tradicionales son los miembros de una comunidad indígena que ejercen, dentro de la estructura propia de la respectiva cultura un poder de organización, gobierno, gestión o control social.

e) Cabildo indígena. Es una entidad pública especial, cuyos integrantes son miembros de las comunidades indígenas, elegidas y reconocidas por ésta, como una organización socio-política tradicional, cuya función es representar legalmente a la comunidad, ejercer la autoridad y realizar las actividades que le atribuyen las leyes; sus usos, costumbres y el reglamento interno de cada comunidad.

\subsubsection{Tercera fase. 1992 - 1996. Participación política}

Esta tercera fase se caracteriza por el positivismo generado por logros obtenidos en la Asamblea Nacional Constituyente. Durante los años siguientes los pueblos indígenas de todo el país fundaron organizaciones para garantizar su participación en los procesos, negociaciones y convenios con el gobierno nacional y la comunidad internacional. A su vez, el Gobierno colombiano desarrollaba proyectos para garantizar los derechos fundamentales de las etnias entre los cuales se encuentran:

- Programa de Apoyo y Fortalecimiento Étnico de los Pueblos Indígenas de Colombia, 1995-1998.

- Programa Nacional de Etnoeducación, 1996.

\footnotetext{
7 La Reserva indígena se encuentra organizada en "Resguardos" reconocidos jurídicamente como propiedades colectivas intransferibles (C.P.C Art. 329), fueron establecidos geográficamente por el Gobierno Nacional y las autoridades indígenas de acuerdo a la Ley Orgánica de Ordenamiento Territorial. Estos tienen su origen en los "Resguardos de Indios" establecidos por Carlos V, en 1542 e implantados en la Nueva Granada a finales del siglo XVI, y con ello se referían a las tierras asignadas por la Corona a los pueblos indígenas en usufructo, cediéndoles el derecho de habitación, más no la propiedad. Los pueblos permanecieron años sin tener la titularidad de los resguardos, y sólo hasta el año de 1962 se inicia el proceso de recuperación de las tierras, petición fundamentada en una ley instaurada durante la presidencia de Simón Bolívar, en la cual se devolvían a todos los naturales sus tierras.
} 
- Comisión de Derechos Humanos de los Pueblos, 1996.

- Comisión Nacional de Territorios Indígenas, 1996.

\subsubsection{Cuarta fase. $1997-2005$. Resistencia a la guerra}

El resurgir socio-político de las comunidades indígenas entre la década de los 80 e inicios de los 90 se ve afectada por el conflicto armado que azotaba a todo el país. Los asesinatos políticos por parte de los grupos paramilitares y guerrilleros alcanzaron a los líderes indígenas en la Sierra Nevada de Santa Marta, Cauca y Putumayo. El punto álgido del conflicto fue el año 2002 con un gran número de víctimas indígenas, $298^{8}$. La Oficina en Colombia del Alto Comisionado de Naciones Unidas para los refugiados ACNUR, la Defensoría del Pueblo y la ONIC emitieron un comunicado a las organizaciones internacionales y al Estado colombiano denunciando el etnocidio que se estaba llevando a cabo por la acción de los grupos armados y por la omisión del gobierno.

Ante los múltiples ataques a los que estaban siendo sometidos casi a diario, las comunidades indígenas iniciaron un nuevo ciclo de resistencia no armada. Las manifestaciones y movilizaciones civiles se dieron en todo el territorio con el apoyo de la sociedad colombiana. Ese fue el primer paso para recuperar sus tierras y sus vidas. El segundo paso consistía en anticiparse a los ataques de los grupos subversivos para lo cual crearon una brigada de vigilancia conformada por voluntarios de los diferentes Cabildos a la que denominaron "La Guardia" y que dependía de los Alguaciles, los encargados de la seguridad en el interior de la comunidad. La acción defensiva de las etnias se vería reforzada con la aplicación de la Justicia Indígena para todos aquellos que atentaran contra la integridad de las personas y el territorio. Decisión que fundamentaron con el Artículo 246 de la Constitución Política de 1991:

Las autoridades de los pueblos indígenas podrán ejercer acciones jurisdiccionales, dentro de su ámbito territorial, de conformidad con sus propias normas y procedimientos, siempre que no sea contrario a la constitución y leyes de la república. La ley establecerá las formas de coordinación con esta jurisdicción especial con el sistema judicial nacional. ${ }^{9}$

Sin embargo, la estrategia de resistencia de los pueblos originarios fue mucho más allá. El 12 de julio del año 2002 los habitantes de Toribio, un pueblo indígena del departamento del Cauca donde se habían realizado múltiples manifestaciones, se enfrentaron sin armas a 400 guerrilleros de las FARC. Su objetivo: salvar la vida de 14 policías que habían estado 20 horas combatiendo contra los subversivos. La valentía de la

\footnotetext{
${ }^{8}$ Villa, W. \& Houghton, H. (2005). Violencia política contra los pueblos indígenas de Colombia. $1974-2004$. Bogotá. CECOIN - OIA, p. 47.

9 Constitución Política de Colombia obtenido en http://www.constitucioncolombia.com/titulo-8/capitulo5/articulo-246
} 
comunidad, liderada por el Párroco, hizo que el comandante de las FARC dejara libre a los agentes $^{10}$. A partir de entonces Toribio es considerado un símbolo de resistencia y su alcalde Ezequiel Vitonás, quien en 2001 había sido declarado por la UNESCO como "Maestro de Sabiduría, fue elegido personaje del año por el diario El Tiempo, en diciembre de 2004. Un reconocimiento a su valor y liderazgo en las diversas manifestaciones que esta comunidad de 26 mil habitantes ( $90 \%$ de la etnia Páez y el 10\% restante guambiano) habían celebrado durante años contra los grupos armados. De igual manera, en el mismo año, las comunidades indígenas del Cauca recibieron el Premio Ecuatorial ${ }^{11}$ I y "La Guardia" fue galardonada con el Premio Nacional de Paz.

\subsubsection{Quinta fase. 2005 - actualidad. Diálogo y comunicación intercultural}

Esta quinta fase está marcada por los mandatos presidenciales de Juan Manuel Santos Calderón, quien ha establecido un punto de inflexión en la forma de interacción entre el gobierno y los grupos étnicos. En su primer periodo presidencial en el año 2010, como gesto de respeto y aceptación de las tradiciones indígenas, solicitó a las cuatro etnias que habitan la Sierra Nevada de Santa Marta (Arhuacos, Koguis, Wiwas y Kankuamos) una ceremonia de transmisión de mando para iniciar su gobierno en armonía con las leyes naturales.

El siete de agosto de 2010, horas antes de la ceremonia de posesión en la ciudad de Santa Fe de Bogotá, el Presidente electo, acompañado por su esposa María Clemencia y sus hijos Martín, Esteban y María Antonia, viajaron hasta la parte alta, al norte de la Sierra, en donde la comunidad indígena representada por los Mamos Mayores, autoridad tradicional de los cuatro pueblos, y los cabildos de las organizaciones indígenas le esperaban. La ceremonia de posesión se celebró en Seijua, en donde se encuentra uno de los templos ceremoniales más importantes de los Kogui.

Para el acto, toda la familia presidencial vestía de blanco. Además, el Presidente y sus hijos iban descalzos como la población indígena. El protocolo de la ceremonia lo marcaron los Mamos y el primer paso consistió en un ritual público, por medio del cual pedían permiso a los ancestros para celebrar la ceremonia. Seguidamente les entregaron al Presidente Santos y a cada miembro de su familia unos hilos donde debían depositar de manera simbólica sus pensamientos y reflexiones.

\footnotetext{
${ }^{10}$ Toribio salvó a sus policías (2012, 13 de julio). El Tiempo. Obtenido en: http://www.eltiempo.com/

${ }^{11}$ El Premio Ecuatorial es otorgado por el Programa de las Naciones Unidas para el Desarrollo (PNUD). Su objetivo principal es reconocer soluciones locales para la gente, la naturaleza y la capacidad de recuperación o adaptación de las comunidades.
} 


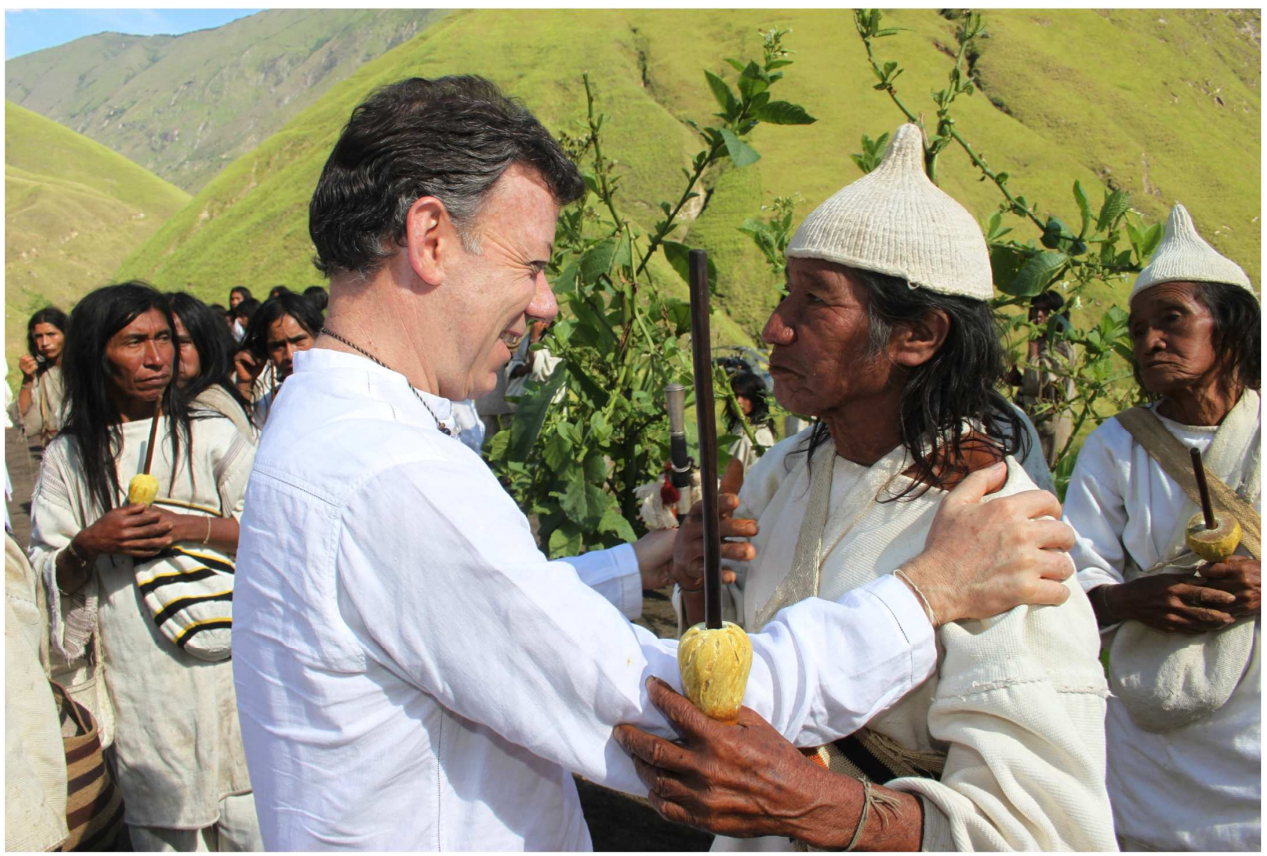

Juan Manuel Santos y Mamo Kogui. Fuente web Presidencia de la República de Colombia

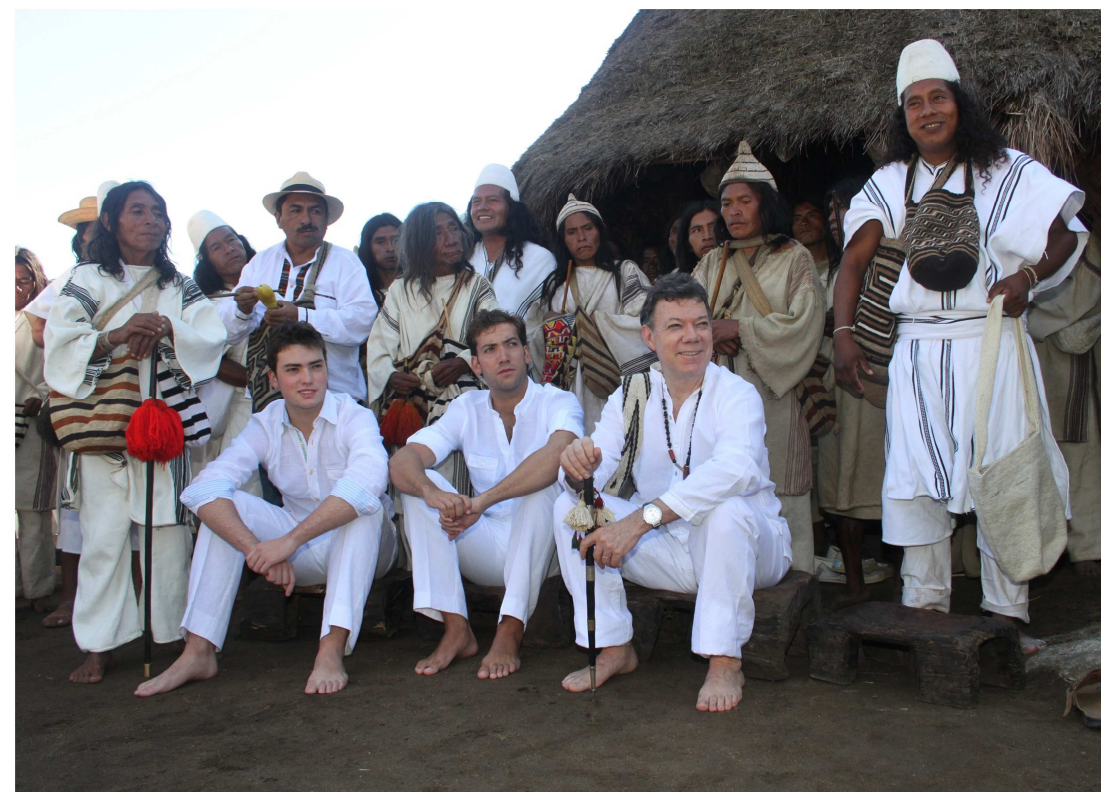

Fuente web Presidencia de la República de Colombia

El presidente y sus dos hijos fueron guiados por los Mamos Mayores al templo masculino para un ritual privado en donde se le fue impuesto un collar con cuatro piedras semipreciosas de origen tairona llamadas "tumas" que representan el gobierno, el agua y el mar, la tierra y los alimento; unas "aseguranzas" en las muñecas, el "Bastón de mando" y una mochila. Su esposa e hija participaron a la vez de un ritual alterno, en el templo 
femenino, en el cual le entregaron a la esposa un huso que simboliza la forma en que se debe tejer la vida, un collar de cuarzos y una mochila. (Serpa, 2015).

Durante sus mandatos el Presidente Santos ha seguido interactuando con las etnias. Tanto él como su equipo de gobierno han participado de forma activa en los rituales y ceremonias a los que han asistido en las negociaciones, diálogos y convenios con los líderes de las comunidades indígenas.

\subsection{El Protocolo Intercultural, derribando barreras de comunicación}

En el apartado anterior se ha analizado desde un contexto histórico, social y político la comunicación entre el gobierno colombiano y las comunidades indígenas hasta la actualidad. En la quinta y última fase se evidencia un cambio, no solo en la comunicación sino también en la interacción entre las partes. En este cambio el gran aliado del Gobierno ha sido el Protocolo Intercultural. A través de él, el Presidente Santos se ganó la confianza y el respeto de los pueblos originarios, aplicando tres aspectos fundamentales y son: respeto a la diversidad cultural, una comunicación intercultural eficaz y el principio de reciprocidad indígena.

\subsubsection{Diversidad cultural}

La diversidad cultural es considerada por la UNESCO como patrimonio común de la humanidad. En su Declaración Universal (2002), establece:

La diversidad cultural no puede resumirse en un agregado de diferencias culturales, lingüísticas u otras. Es una "aptitud" anticipada que debe promoverse en términos de principios, normas y prácticas. Cuando a la diversidad cultural se le considera solo en forma pasiva, como simple mosaico de colores, disminuirá lentamente, como si esos colores se fusionaran o diluyeran. Cuando a la diversidad cultural se le concibe en términos activos, como un proceso que necesita ejercitarse, entonces se desplegará como un abanico en toda su policromía" (p. 20).

Esa "aptitud anticipada que debe promoverse en términos de principios, normas y prácticas" es la que rige el Protocolo Intercultural, y fue la base sobre la cual el Presidente Santos gestionó su interacción con las etnias:

- Principios. Para lograr una excelente comunicación entre culturas (independientemente del campo de actuación) es muy importante el respeto a los principios, considerados parte intrínseca del ser humano, porque sobre ellos se constituyen las comunidades.

- Normas. Toda sociedad primitiva o civilizada necesita de reglas o códigos de conducta para mantener el orden social. Las normas de convivencia sociales y las jurídicas imponen sanciones sobre actos que atenten contra la moral, la ética, los bienes, los derechos y obligaciones de sus miembros. 
- Prácticas. Llevar a cabo una relación de convivencia, negocios o una simple conversación teniendo en cuenta los principios y las normas de cada cultura, garantizan el éxito de la misma.

\subsubsection{Comunicación Intercultural.}

"La comunicación intercultural no se produce de forma descontextualizada. Toda comunicación se produce en unas circunstancias determinadas, que modifican las características del proceso comunicativo" (Rodrigo, 2011, p. 8). El Presidente Santos comprendió que en el momento de solicitar una ceremonia de transmisión de mando indígena, debía adaptarse a todas y cada una de las circunstancias a las que hace referencia Miquel Rodrigo Alsina, y para el caso serían: el escenario, la indumentaria y la simbología. De igual manera, para que la comunicación resultara eficaz aplicó los siguientes elementos ${ }^{12}$ :

- Una lengua en común.

- El conocimiento de la cultura ajena.

- El re-conocimiento de la cultura propia.

- La eliminación de prejuicios.

- Ser capaz de empatizar.

- Saber meta comunicarse.

- Tener una relación equilibrada.

\subsubsection{Principio de Reciprocidad.}

Para los indígenas consiste en devolverle a la Madre Naturaleza de manera simbólica, a través de ritos y ceremonias, todo lo que les ha dado (territorio, alimentos, etc.). Este principio abarca lo que los indígenas definen como Derecho Mayor que no es otro que el derecho al territorio para el desarrollo de su cultura.

Salir del territorio no es solamente una pérdida de la propiedad o un cambio de domicilio brusco o violento, sino la pérdida de los referentes que permiten la reproducción de las culturas. Para estos pueblos la cultura no puede reproducirse en otra región del país porque la existencia tiene una relación directa y sustancial con sus territorios; de hecho, la definición de ser indígena o de pertenecer a uno de los linajes, está determinada por el lugar de nacimiento y residencia [...] Los territorios en que las culturas indígenas se han construido son reducidos en términos físicos pero tienen como correlato una fuerte carga simbólica; los

\footnotetext{
${ }^{12}$ Rodrigo, M. (2011). La Comunicación Intercultural. Obtenido en: www.portalcomunicacion.com/
} 
pueblos indígenas han marcado espiritual y políticamente sus territorios, éstos se encuentran incorporados en sus cosmovisiones y en la mayoría de las culturas tienen carácter de "sujetos espirituales". (ONIC, citado por Villa \& Houghton, 2005, p. 221)

\subsection{Las Relaciones Públicas, el Medio Ambiente y el nuevo discurso indigenista}

En América Latina existen más de $800^{13}$ pueblos indígenas que tienen como herencia sus tradiciones y como escenario para su aplicación el territorio, el cual abarca tres dimensiones: biológica, geográfica y cosmogónica. Para las comunidades indígenas los bosques, los ríos, todos los seres vivos que habitan los páramos y las selvas cumplen una función dentro del ecosistema que permite el equilibrio natural entre las especies, lo anterior desde la perspectiva biológica. Desde el punto de vista geográfico existe una íntima relación entre los indígenas y su entorno, es decir, se identifica a cada etnia por el lugar que ocupa dentro de la geografía de su país el cual ha determinado su modo de vida y esto incluye el atuendo, la vivienda y las actividades agropecuarias. Desde el punto de vista cosmogónico la mayoría de las etnias tienen su propia visión de la creación pero tienen en común a un principio creador que les protege y les provee de los recursos necesarios para subsistir. Para los pueblos este principio creador es palpable, tiene diferentes texturas, colores y olores y lo más importante: abarca en su seno a todas las especies y no es otra que la Madre Naturaleza. Cada elemento de natura, según la filosofía indígena, tiene un papel fundamental en la cadena de energía cósmica que ayuda a mantener el equilibrio natural y espiritual del planeta.

Con el surgimiento de los movimientos indígenas a finales del siglo XIX e inicios del siglo XX, la población indígena inicia un largo proceso de recuperación de los territorios ancestrales ${ }^{14}$.

\footnotetext{
${ }^{13}$ Comisión Económica para América latina y el Caribe "CEPAL". (2014). Los Pueblos Indígenas en América Latina: Avances en el último decenio y retos pendientes para la garantía de sus derechos. Santiago de Chile: Organización de las Naciones Unidas.

${ }^{14}$ Aunque el movimiento indígena surgió partir de los 80 con la expulsión de las Misiones Evangelizadoras y la restitución de las tierras, solo hasta 1992 con la Cumbre de Rio los pueblos indígenas encontrarían en "la problemática ambiental" a su mejor aliado para la protección y defensa de su territorio. Desde entonces se ha reconocido a los pueblos indígenas como los primeros comunicadores y educadores ambientales, acciones que son parte de sus creencias y tradiciones porque para ellos lo más importante es la naturaleza y su territorio. Con esta premisa el Foro Permanente para las Cuestiones Indígenas (UNPFII) recomienda al PNUMA adoptar una política sobre pueblos indígenas y asegurar la participación completa y efectiva de estos en la formulación de la misma, así como en sus programas y proyectos (PNUMA. Programa de las Naciones Unidas para el Medio Ambiente, 2012, p. 1). A partir de esta recomendación el PNUMA en noviembre 2012 suscribe una alianza con los pueblos indígenas para el cuidado del medio ambiente apoyándose en los siguientes documentos y declaraciones (p. 4):

- $\quad$ El Convenio sobre Pueblos Indígenas y Tribales en Países Independientes de 1989.

- La Declaración de Malmö de 2000. “El éxito de la lucha contra el deterioro ambiental depende enteramente de la participación de todos los actores sociales, de una población informada y consciente, del respeto a los valores éticos y espirituales de la diversidad cultural y la preservación del legado y conocimiento indígenas"

- Decisión 21/19 del Consejo de Administración de 2001.

- Decisión SSVII.5 del Consejo de Administración de 2002.
} 
Aprovecha el interés que despierta sus tradiciones en personalidades de diferentes ámbitos sociales para hacer un llamamiento sobre la importancia de su territorio. Descubren que “influir en las mayorías puede ser de gran ayuda" ${ }^{15}$. Un ejemplo de ello es el líder indígena Raoni Metuktire ${ }^{16}$ de la etnia Kayapó, un pueblo indígena que habita la amazonia brasileña, quien, sin saberlo, utilizó el concepto de propaganda expuesto por Bernays (2008, p. 38)

La nueva propaganda no sólo se ocupa del individuo o de la mente colectiva, sino también y especialmente de la anatomía de la sociedad, con sus formaciones, lealtades de grupos entrelazadas. Concibe el individuo no sólo como una célula en el organismo social sino como una célula organizada en la unidad social. Basta tocar una fibra en el punto sensible para obtener una respuesta inmediata de ciertos miembros específicos del organismo.

En octubre de 1988, el líder indígena y el cantante Sting, participaron en una conferencia organizada por Amnistía Internacional sobre los derechos humanos en Sao Paulo, Brasil. Y en febrero de 1989 inician una campaña por 17 países que tenía como finalidad concienciar a la humanidad sobre la importancia de proteger los bosques de la región amazónica. La campaña tuvo como resultado el reconocimiento del Parque Xingú a nivel mundial, pero además contó con el apoyo de los jefes de estado de Francia, España, Ciudad del Vaticano y el Príncipe de Gales, entre otros.

Las relaciones públicas han utilizado la técnica de la persuasión para llegar a las masas. Esta técnica toma a figuras influyentes de la sociedad como cantantes, actores, y deportistas para llegar a los diferentes públicos. La repercusión mediática de esta campaña

- Medio ambiente y diversidad cultural. El 22o periodo de sesiones del Consejo de Administración/Foro Ambiental Mundial a nivel Ministerial se adoptó la decisión "Medio ambiente y diversidad cultural" en la que se solicitaba un estudio en colaboración con la UNESCO sobre la situación actual y posibles avances.

- Plan Estratégico de Bali para el apoyo tecnológico y la creación de capacidad de 2005.

- Declaración de la ONU sobre los derechos de los pueblos indígenas el 13 de septiembre de 2007.

- Directrices sobre las Cuestiones indígenas del Grupo de las Naciones Unidas para el desarrollo (GNUD) de 2008.

${ }^{15}$ Bernays, E. (2008). Propaganda. España: Melusina.

${ }^{16}$ El líder indígena tocó la fibra sensible del cantante Sting, de su esposa Trudy Stiler y del cineasta belga Jean Pierre Dutilleux quienes fueron cofundadores de la Rainforest Foundation, una organización que apoyaba los proyectos de este carismático líder cuyo objetivo principal era delimitar y proteger el territorio Kapayó de la invasión de los colonos y de la explotación de los recursos naturales por parte de empresas del sector energético. Su lucha principal se centró en impedir la construcción de una presa (proyecto Belo Monte) que comprendía una gran extensión del rio Xingú, el mayor afluente del río Amazonas y cuyo recorrido abarca los estados de Mato Grosso y Pará. En el año 1969, el presidente Janio Quadros, declara la cabecera de este río como "Parque Nacional Indígena Xingú". En él, habitan 5.500 indígenas de 14 etnias. Los encuentros de Raoni y Sting se iniciaron en 1987 en el Parque Nacional Indígena Xingú, año en el que la Comisión Mundial del Medio Ambiente y Desarrollo presentaba el Informe "Nuestro futuro en común" y hacía un llamamiento a los líderes mundiales: "Quizás nuestra tarea más urgente es la de persuadir a las Naciones de que necesiten volver al multilateralismo" (Comisión Mundial sobre el Medio Ambiente y el Desarrollo, 1987, p. 11). 
tuvo en sí a tres protagonistas: un líder indígena que solo con su apariencia comunica sus tradiciones y costumbres; un cantante irreverente y una problemática ambiental que dejaba de ser el problema de unos para convertirse en el gran enemigo de todos

Por otra parte, en Colombia, la formación académica y el uso de las tecnologías de la información y la comunicación de los líderes indígenas han sido fundamental en su participación en la vida social, política y cultural del país. Danilo Villafañe, líder arhuaco de la Sierra Nevada de Santa Marta, desde 1996 es el Coordinador de Territorio y Medio Ambiente de la Organización Indígena Gonawindúa Tairona y Asesor del Concejo Territorial de Cabildos Indígenas de la Sierra Nevada. Ha sido conferenciante en empresas privadas colombianas, en eventos de difusión en la London School of Economics y varias universidades nacionales e internacionales. Conferenciante y miembro permanente de Transformative Business Leadership, del Centro de Liderazgo y Gestión y conferencista en Expogestión, miembro de la Junta Directiva de Amazon Conservation Team (ACT); Delegado de la Mesa Permanente de Concertación por la Confederación Indígena Tayrona, Delegado de la Comisión Nacional de Territorios Indígenas, miembro de la Junta Directiva de la Fundación Prosperidad Colectiva, participante de Evolución Colombia; coordinador, organizador y gestor del programa de Apoyo para el Corazón del Mundo (Consolidación Territorial de la Sierra Nevada de Santa Marta) de 2006 a 2010.

Danilo Villafañe es un ejemplo de la "reinvención de la cuestión indígena por parte de los propios dirigentes indígenas" (Bengoa, 2000, p. 19). Este joven líder de la etnia arhuaca ha desarrollado una conciencia étnica, puesto que ya no se trata solo de que los gobiernos cumplan con las demandas indígenas -que incluían principalmente la restitución de las tierras-, sino que además, exigen que reconozcan su identidad y les permitan participar activamente en la sociedad. Estos son los elementos del nuevo discurso indígena: territorio, cultura y autonomía los tres principios básicos sobre los cuales se construye su vida.

\section{CONCLUSIÓN}

El gobierno colombiano ha encontrado en el Protocolo Intercultural a su mejor aliado en la gestión de la comunicación con las comunidades indígenas. Tras el análisis de los componentes que intervienen en dicha interacción, podría definirse al Protocolo Intercultural como el conjunto de principios, normas y prácticas que rigen el diálogo entre culturas. El principio rector de los pueblos indígenas es el respeto y conservación del medio ambiente. Toda su existencia se rige por los elementos que lo conforman siendo su vida un ceremonial permanente dictado por normas y leyes ancestrales que encuentra en la naturaleza la razón de su existencia. Cuando un indígena ve amenazado su territorio recurre a métodos como las relaciones públicas, que siendo desconocidos para él, desde lo conceptual, lo aplica porque sabe que su imagen -esa que tanto gusta por lo exótico y natural- es un espejo en donde la sociedad civilizada se ve deformada.

Los líderes indígenas han sido sus propios asesores en relaciones públicas. Han conseguido un gran impacto en la sociedad, tanto así que las multinacionales encuentran en 
estas comunidades un gran obstáculo para la consecución de sus objetivos tal y como señala este artículo:

Tomar en cuenta la opinión de los indígenas es un factor decisivo para el éxito o fracaso de una empresa cuando se trata de invertir dentro de lo que se considera su territorio en América del Sur. La historia demuestra que ignorarlos puede llevar al fracaso de cualquier iniciativa y afectar irremediablemente la imagen corporativa a nivel nacional. (Chocano, citado por Bengoa, 2000, p. 25)

El discurso indígena actual tiene una alta dosis de conciencia étnica, de formación y preparación. Saben que una imagen vale más que mil palabras y que la forma como se transmite ese mensaje creará conciencia pública.

\section{BIBLIOGRAFÍA}

ARANGO, R. (2004). Los pueblos indígenas de Colombia en el umbral del nuevo milenio: población, cultura y territorio : bases para el fortalecimiento social y económico de los pueblos indígenas. Bogotá: Departamento Nacional de Planeación.

BENGOA, J. (2000). La emergencia indígena en América Latina. Santiago: Fondo de Cultura Económica de Chile S.A.

CENTRO DE ESTUDIOS CONSTITUCIONALES-PLURAL. (4 de Julio de 2011). El paso a paso del proceso constituyente. Recuperado el 10 de febrero de 2018, de Revista Semana: https://www.semana.com/nacion/articulo/el-paso-paso-del-proceso-constituyente/238038-

COMISIÓN ECONÓMICA PARA AMÉRICA LATINA Y EL CARIBE "CEPAL". (2017). Los pueblos indígenas en América (Abya Yala). Santiago. CEPAL.

SÁNCHEZ, E. \& MOLINA, H. (Comp). (2010). Documentos para la historia del movimiento indígena colombiano contemporáneo. Bogotá. Dirección de Poblaciones, Ministerio de Cultura de la República de Colombia.

MINISTERIO DE JUSTICIA DE LA REPÚBLICA DE COLOMBIA. (20 de Diciembre de 1961). Sistema único de Información Normativa. Obtenido de http://www.suin.gov.co

PEÑARANDA, D. (2015). Guerra propia, Guerra ajena. Conflicto armado y reconstrucción identitaria de los Andes colombianos. El movimiento armado de Quintín Lame. Bogotá. Centro Nacional de Memoria Histórica.

REDACCIÓN EL TIEMPO. (12 de Julio de 2002). Toribio salvó a sus policias. El Tiempo.

RODRIGO, M. (9 de Septiembre de 2011). Portal de Comunicación. Obtenido de http://portalcomunicacion.com/uploads/pdf/1_esp.pdf 
SERPA, Y. (2015). Ceremonial del ciclo vital de las etnias Kogui y Arhuaca de la Sierra Nevada de Santa Marta, Colombia. Madrid. Manuscrito no publicado.

VILLA, W., \& HOUGHTON, J. (2005). Violencia política contra los pueblos indígenas de Colombia. 1974-2004. Bogotá. CECOIN - OIA. 